\title{
Economic Efficiency in Barely Production: The Case of Chole District, East Arsi Zone, Oromia National Regional State, Ethiopia
}

\author{
Mustefa Bati(Assistant Professor) ${ }^{1^{*}} \quad$ Jema Haji (Professor) ${ }^{2}$ \\ 1. Department of Agricultural Economics, Mettu University, Ethiopia \\ 2. School of Agricultural Economics and Agribusiness, Haramaya University, Ethiopia
}

\begin{abstract}
As the world's population grows and the potential to increase production by bringing more resources into use becomes more limited, it is natural that the efficiency with which farmers use available resources would become more important as a topic of investigation. Therefore, this study aimed at analyzing the economic efficiency of barley production in Chole district using cross sectional data collected from 150 randomly selected sample households during 2012/13 production season. Cobb-Douglas production function was fitted using stochastic production frontier approach to estimate technical, allocative and economic efficiency levels, whereas Tobit model was used to identify factors affecting efficiency levels of the sample farmer. The results indicated that there was a significant inefficiency in barley production in the study area. Accordingly, the mean technical, allocative and economic efficiencies of barley producer farmers were $78.20,46.05$ and 35.26 percent, respectively. This implies that output can be increased by 21.8 percent or cost can be reduced by 53.95 percent given the existing level of technology and resources. This inefficiency however, can be improved if factors that determine efficiency level of farmers in the production of barley in the study area are identified and targeted. Results of the Tobit model revealed that age, education, total cultivated land, extension contact, family size, soil fertility, off/non-farm income, sex, crop rotation and livestock ownership positively and significantly affected technical efficiency while land fragmentation and total expenditure had negative and significant effect. Result of the Tobit model also revealed that age, education, total cultivated land, training, crop rotation and livestock ownership positively and significantly affected allocative efficiency while extension contact, land fragmentation, distance of the farm from homestead, and total expenditure were found to have negative and significant effect. Among the factors hypothesized to affect the level of economic efficiency, age, education, training, family size, off/non-farm income, crop rotation and livestock ownership were found to have positive and significant effect on economic efficiency in barley production. The results of the study indicated that there was a room to increase the efficiency of barley producers in the study area through policies and strategies directed towards the above mentioned determinants.
\end{abstract}

Keywords: Cobb-Douglas, stochastic frontier, Tobit.

DOI: $10.7176 / \mathrm{JRDM} / 66-03$

Publication date:June 30th 2020

\section{Introduction}

Ethiopia, the country with an area of about 1.12 million square kilometers, is one of the most populous Counties in Africa with the population of 73.75 million in 2007 with annual growth rate of $2.6 \%$ (CSA, 2008). The projected figure for the year 2013 was 86.51 million (CSA, 2013). This growing population requires better economic performance than ever before at least to insure food security. However, the agricultural sector in the country is characterized by; small-scale, subsistence-oriented, an adverse combination of agro climatic, demographic, economic and institutional constraints and shocks and heavily dependent on rainfall.

Ethiopian agricultural sector contributes about $41 \%$ of the country's GDP, employs $83 \%$ of total labour force and contributes $90 \%$ of exports (EEA, 2012). The sector plays a pivotal role to induce the industrialization process in the country. Therefore, enhancing the productivity of such sector is crucial not only for the development of the sector themselves but also for the development of other sectors in the economy.

Ethiopia is the country with largest grain producers in Africa. However, it is characterized by large pockets of food insecurity and a net importer of grains. Despite its dominance, WFP (2013) indicated that there were more than seven million peoples in need of food assistance in the country. The country is food insecure mainly due to lack of improved technology and economic inefficiency in production. The smallholder farmers, who are providing the major share of the agricultural output in the country, commonly employ backward production technology and limited modern inputs (World Bank, 2007). Hence, being an agriculturally dependent country with a food deficit, increasing crop production and productivity is not a matter of choice rather a must to attain food self-sufficiency.

Barley is one of the most important food crops in the world in general and in Ethiopia in particular for a long period of time. In volume of world crop production, it ranks the fourth and ranks the fifth for Ethiopia (CSA, 2012). It originated in Ethiopia and Southeast Asia, where it has been cultivated for more than 10,000 years (Badr, 2000). It was used by ancient civilizations as a food for humans and animals, as well as to make alcoholic beverages. 
According to CSA (2013), in 2012/13 production year, barley covered 1.02 million ha of land at national level. The total production of barley in the same year at national level was 17.82 million qt. In the same year, the total productivity of the crop at national level was 17.49 qt per ha. From 2011/12 to 2012/13, production of barley has increased by $12.39 \%$ and productivity has improved only by $4.61 \%$ at national level.

The same source indicated that in Oromia region, the total area covered by barley in the production year of 2012/13 was 448.55 thousand ha and 8.98 million qt of barley have been produced with the productivity of 20.01 qt per ha. East Arsi zone produced 2.27 million qt of barley from 93,757.41 ha of land with productivity of 24.2 qt per ha.

Chole district, which is one of the districts of East Arsi zone, is known by cereal production specially barley and wheat. Out of the total 68,200 hectares of land in the district, land used for cultivation occupies 48.30 percent. Out of this total cultivated land, barley occupies 18.40 percent. Farmers in the district produce barley and supply it to Asella malt factory and to other domestic consumers. In 2012/13 production year, the total production and productivity of barley in the district was $1,16,245 \mathrm{qt}$ and $19.20 \mathrm{qt}$ per ha respectively (CDARDO, 2013). Hence, this study tries to analyze the economic efficiency of barley production, and its determinants in one of the districts of East Arsi zone, known for the production of this crop, Chole.

Though agriculture is the corner-stone of Ethiopian economy, its performance has been unsatisfactory and unable to meet the ever increasing demand of the increasing population. This is mainly attributed to the poor use of modern inputs such as fertilizers, improved seeds and extension services which partly explain the lower productivity of the sector and apart from this, the internal inefficiency of the farmers in using the available agricultural resources such as land and labor (Kinde, 2005). Therefore, increasing productivity of the sector is essential. Its productivity can be increased through technology adoption, improvement in efficiency of production and/or resource reallocation. These are not exclusive because the introduction of modern technology could not bring the expected shift in production frontier, if the existing level of efficiency is low. This implies the need for the integration of modern technologies with improved level of efficiency.

In developing countries like Ethiopia, new technologies have partially succeeded in improving productivity due to institutional and cultural constraints (Crissman et al., 2006). If farmers are efficiently using the existing technologies, then ways of improving productivity will be more cost effective in the short run than introducing new technologies. Unless the potential of existing technology is known and completely exploited, the benefits from new one may not be realized in the short run. Theoretically, introducing modern technology can increase agricultural output. However, in areas where there is inefficiency, trying to introduce new technologies may not have the expected impact and "there is danger of trying to rediscover the wheel" if existing knowledge is not efficiently utilized (Tarkmani and Hardakar, 1996 as cited in Getu, 1997).

Barley is a wonderful cereal crop that has a great advantage. Thus, due attention should be given to strengthen the production and productivity of this crop. However, there is limited number of studies done in this regard in general and there is no similar study has been done on economic efficiency of smallholder barley producers in Ethiopia, particularly in the study area. Hence, there is a need to fill this gap and provide possible intervention areas to improve the existing barley production and productivity.

Moreover, promoting economic efficiency at farm level under the existing technology is very important to enhance the contributions of the sector to the national economy. Actually, inefficiency is costly both to the producing units and to the society at large. Hence, identifying the extent of inefficiency and the factors that contribute to it is of a paramount importance. Besides, such information is useful for formulating appropriate policies and for reducing the level of economic inefficiency.

There were few studies that were conducted on efficiency of barley production in Ethiopia. However, their scope is limited to the measurement of technical efficiency (Mohammed, 1999; Wadi'ah, 2012), even though it is by improving the overall economic efficiency that major gains in production of barley could be achieved. Hence, this study was aimed to examine the importance of both allocative and economic efficiencies on performance of barley production.

The average barley productivity in the study area, Chole is only 14 quintals per hectare for some farmers and 27 quintals per hectare for some other farmers (CDRADO, 2013). This shows that there were productivity variations among farmers in the study area and this is another reason why this study focused on economic efficiency in barley production and its determinants which causes efficiency differentials among farmers in the study area.

\section{Objectives of the Study}

The general objective of the study was to assess economic efficiency of barley producers in Chole district of East Arsi zone. The specific objectives of the study were:

i. To estimate technical, allocative and economic efficiencies of barley producers in the study area; and ii. To identify factors affecting technical, allocative and economic efficiencies of barley producers in the study area. 


\section{Methodology}

\section{Description of the Study Area}

Chole district is located in Oromia National Regional State of East Arsi Zone at about $219 \mathrm{~km}$ away from Addis Ababa. It is located at $6^{0} 22^{\prime}$ and $8^{\circ} 14^{\prime} \mathrm{N}$ latitude and $40^{\circ} 02^{\prime}$ and $40^{\circ} 19^{\prime} \mathrm{E}$ longitude. Asako district borders it to the north. The Guna district borders it to the west. Gololcha and Sude districts borders to the east and south respectively. The administrative center of the district is Chole town.

The district has 18 rural kebeles, out of which 16 of which participate in barley production. The 2007 national census reported a total population of the district to be 105,614 people, of whom 52,888 were male and 52726 were female. Out of the total area of 68,200 ha, crop land accounts for 21,824 ha.

Figure 1: Location of Chole district

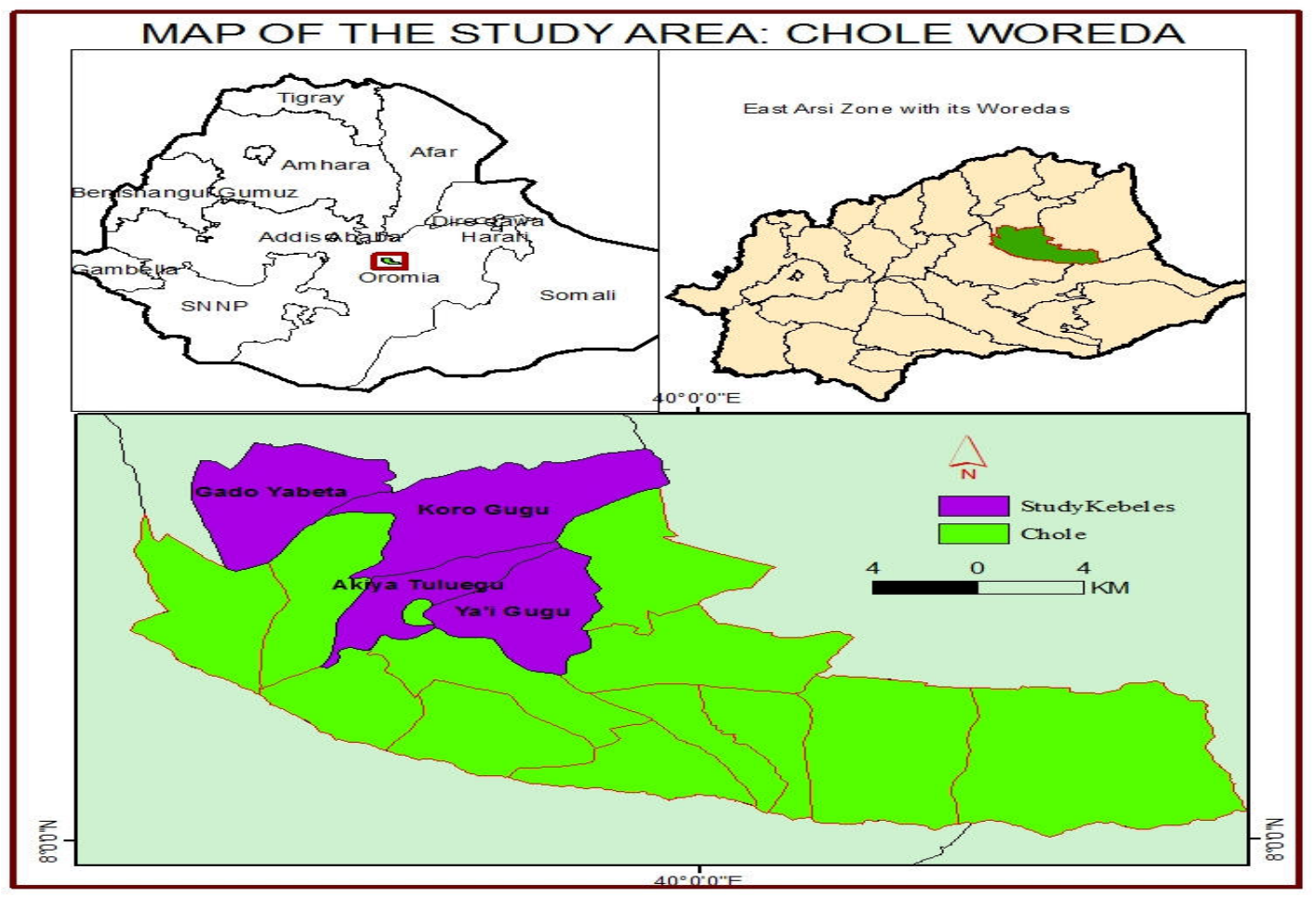

Types and Methods of Data Collection

The study was based on both primary and secondary data. It were employed primary data that were collected from the sample farm households. Secondary data which are relevant were also gathered from governmental and nongovernmental sources located around the study area so as to backup the primary data. These were including both published and unpublished documents.

\section{Sampling Techniques}

Chole district was purposively selected for the study because of the presence of large number of barley producing farmers and its production potential for barley. To determine the sample kebeles and households, a two stage stratified random sampling procedures were used. In the first stage, kebeles were stratified as those which producing and not producing barley. Then, four kebeles out of sixteen barley producing kebeles were selected randomly. In the second stage, households in each four selected kebeles were stratified into those who were producing barley and those who were not producing barley. Then, 150 farm households were selected randomly from those who were producing barley taking into account probability proportional to the size of barley producer farmers in each of the four selected Kebeles. The sample size was determined based on the following formula given by (Yamane, 1967).

$$
\mathrm{n}=\frac{N}{1+N\left(e^{2}\right)}
$$

Where, $\mathrm{n}$ is sample size, $\mathrm{N}$ is number of household head and $\mathrm{e}$ is the desired level of precision. By taking e as 
$8.2 \%$, total population 105,614 and 5.84 average family size of the district CSA (2012), the sample size would be 149. However, data were gathered from 150 households.

\section{Methods of Data Analysis}

To address the objectives of the study, descriptive and econometric methods of data analysis were employed. Accordingly, in the descriptive part, simple measures of central tendencies and variations, frequency and percentages were used; and in the econometric analyses, a stochastic frontier approach was used to estimate the level of barley production efficiencies and a Tobit model to identify factors that affect the efficiency level of the farmers.

\section{Specification of the econometric models Efficiency measurement}

The SFP approach offers some sensible advantages over the other methods that are usually used in efficiency analysis. In the first place, it is easy to implement and interpret. Most importantly, the model allows segregating the effect of statistical noises from systematic sources of inefficiency. Besides, the technique is consistent with most of the agricultural production efficiency studies (Kaleab, 2010; Wadi'ah, 2012; Mohamed, 2012; Solomon, 2012).

The assumption that all deviations from the frontier are associated with inefficiency, as assumed in DEA, is difficult to accept, given the inherent variability of agricultural production due to many factors like climatic hazards, plant pathology, insect and pests (Coelli and Battese, 1995). Moreover, Smallholder farmers in Ethiopia in general and in the study area in particular were characterized by low level of education and keeping of records is thus non-existent. Thus, most available data on production are likely to be subject to measurement errors. Therefore, within the stochastic frontier framework, the stochastic efficiency decomposition methodology was chosen as more appropriate for this study. The SFP model for this study was specified as follows:

$Y_{i}=F\left(X_{i} ; \beta\right) \exp \left(V_{i}-U_{i}\right) \mathrm{i}=1,2,3 . . \mathrm{n}(3.2)$

Where $Y_{i}$ is the production of the $\mathrm{i}^{\text {th }}$ farmer, $\mathrm{X}_{\mathrm{i}}$ is a vector of inputs used by the $\mathrm{i}^{\text {th }}$ farmer, $\beta$ is a vector of unknown parameters, $\mathrm{V}_{\mathrm{i}}$ is a random variable which is assumed to be $\mathrm{N}\left(0, \sigma_{v}{ }^{2}\right)$ and independent of the $\mathrm{U}_{\mathrm{i}}$ which is non-negative random variable assumed to account for technical inefficiency in production.

Moreover, the assumptions made about the distributions of the error components $U_{i}$ and $V_{i}$ should be respected (Coelli, 1998). For this study it is assumed that $U_{i}$ and $V_{i}$ are independently and identically distributed half-normal random variables with mean zero and variance $\square^{2}$.

As stochastic frontier method requires a prior specification of the functional form, for this study, CobbDouglas production function was selected. The linear form of Cobb-Douglas production function is represented in Equation 3.2.

$$
\ln Y_{i}=\beta_{0}+\ln \sum_{j=1}^{n} \beta_{j} X_{i j}+\varepsilon_{i}
$$

Where

$\varepsilon_{i}=v_{i}-u_{i} ; \ln =$ denotes the natural logarithm, $j=$ represents the number of inputs used, $i=$ represents the $\mathrm{i}^{\text {th }}$

farmer in the sample,$Y_{i}=$ represents the observed barley production of the $i^{\text {th }}$ farmer, $X_{i j}=$ denotes $j^{\text {th }}$ farmer input variables used in barley production of the $i^{\text {th }}$ farmer, $\beta=$ stands for the vector of unknown parameters to be estimated, $\varepsilon_{i}=$ is a composed disturbance term made up of two elements $\left(v_{i}\right.$ and $\left.u_{i}\right), v_{i}=$ accounts for the stochastic effects beyond the farmer's control, measurement errors as well as other statistical noises and $u_{i}=$ captures the technical inefficiency.

The self-dual nature of the Cobb-Douglas production and cost functions also provides the computational advantage in obtaining the estimates of TE and EE. According to Arega and Rashid (2005), inadequate farm level price data together with little or no input price variation across farms in Ethiopia precludes any econometric estimation of a cost function. This problem will be simplified if one uses functional forms which are not flexible such as Cobb-Douglas production function (Kumbhakar, 1991). The self dual functional form allows the cost frontier to be derived and used to estimate EE when farmers face same price. Beside this, in smallholders farming, the technology is unlikely to be substantially affected by variable returns to scale (Coelli, 1995).

As a result of taking the advantages and disadvantages of both functional forms in to consideration the appropriate functional form that better fit the data was selected after testing the null hypotheses using the generalized likelihood ratio test. The value of the generalized log-likelihood ratio (LR) statistic to test the hypothesis that all interaction terms including the square root specification (in the translog functional form) is equal to zero $\left(H_{0}=b i j=0\right)$ was calculated as:

$\mathrm{LR}=-2[\mathrm{~L}(\mathrm{CD})-\mathrm{L}(\mathrm{Tl})]$

Where: $\mathrm{LR}=$ Generalized log-likelihood ratio 
$\mathrm{L}(\mathrm{Cd})=$ Log-likelihood value of Cobb-Douglas

$\mathrm{L}(\mathrm{Tl})=$ Log-likelihood value of translog

Then this value was compared with the upper $5 \%$ point for the $\chi^{2}$ distribution and decision was made based on that result. The linear functional form of Cobb-Douglas production function used for this study is given by Equation (3.5).

$$
\begin{gathered}
\ln (\text { Output })=\beta_{0}+\beta_{1} \ln (\text { area })+\beta_{2} \ln (\text { Inorganic fertilizers })+\beta_{3} \ln (\text { seed })+\beta_{4} \ln (\text { Labour })+\beta_{5} \ln (\text { Oxen }) \\
+\mathrm{v}_{\mathrm{i}}-\mathrm{u}_{\mathrm{i}}
\end{gathered}
$$

For driving the dual cost frontier, the solution for the minimization problem given in Equation (3.6) is essential.

$$
\begin{aligned}
\operatorname{Min}_{x} C & =\sum_{n} \omega_{n} x_{n} \\
& \text { Subject to } \\
Y_{k}^{i^{*}} & =\hat{\mathrm{A}} \prod_{n} x_{n} \hat{\beta}_{n}
\end{aligned}
$$

Where $\hat{A}=\exp \left(\dot{\beta}_{0}\right), \omega_{n}=$ input prices, $\hat{\beta}=$ parameter estimates of the stochastic production function and $Y_{k}^{i^{*}}=$ input oriented adjusted output level from Equation (3.2).

The following dual cost function will be found by substituting the cost minimizing input quantities into Equation (3.6).

$$
C\left(Y_{k}^{i^{*}}, w\right)=H Y_{k}^{i^{*} \mu} \prod_{n} \omega_{n}^{\alpha_{n}}
$$

Where $\alpha_{n}=\mu \hat{\beta}_{n}, \mu=\left(\sum_{n} \hat{\beta}_{n}\right)^{-1}$ and $H=\frac{1}{\mu}\left(\hat{\mathrm{A}} \prod_{n} \hat{\beta}_{n}^{\hat{\beta}_{n}}\right)^{-\mu}$

Generally, the dual cost frontier function can be represented in general form as follows:

$$
C_{i}=C\left(\omega_{i}, Y_{i}^{i^{*}} ; \alpha\right)
$$

Where $\mathrm{C}_{\mathrm{i}}$ : is the minimum cost of $\mathrm{i}^{\text {th }}$ farm associated with output $\mathrm{Y}_{i}^{i^{*}}, \omega_{i}$ : is the vector of input prices for the $\mathrm{i}^{\text {th }}$ firm,$\alpha$ : is the vector of parameters to be estimated

The economically efficient input vector for the $i^{\text {th }}$ farmer derived by applying Shepard's Lemma and substituting the firms input price and adjusted output level into the resulting system of input demand equations.

$$
\frac{\alpha C_{i}}{\alpha \omega_{n}}=X_{i}^{e}\left(\omega_{i}, Y_{i}^{i^{*}} ; \theta\right)
$$

Where $\theta$ is the vector of parameters and $\mathrm{n}=1,2,3 \ldots \mathrm{N}$ inputs.

The observed, technically and economically efficient cost of production of the $\mathrm{i}^{\text {th }}$ farm are equal to $\omega_{i}^{\prime} X_{i}, \omega_{i}^{\prime} X_{i}^{t}$ and $\omega_{i}^{\prime} X_{i}^{t}$. Those cost measures are used to compute technically and economically efficient indices of the $i^{\text {th }}$ farmer as follows

$$
\begin{aligned}
& T E_{i}=\omega_{i}^{\prime} X_{i}^{t} / \omega_{i}^{\prime} X_{i} \\
& E E_{i}=\omega^{\prime} X_{i}^{t} / \omega_{i}^{\prime} X_{i}
\end{aligned}
$$

Following Farrell (1957), allocative efficiency index of the $i^{\text {th }}$ farmer can be derived from Equations 18 and 19 as follows;

$$
A E_{i}=E E_{i} / T E_{i}=\omega_{i}^{\prime} X_{i}^{t} / \omega_{i}^{\prime} X_{i}^{t}
$$

\section{Determinants of efficiency}

In this study technical, allocative and economic efficiency estimates that were derived from stochastic production frontier were regressed using a censored Tobit model on farm-specific explanatory variables that were explain variation in efficiency across farms. The rationale behind using a Tobit model was that there were a number of 
farm units for which efficiency could be 1 and the bounded nature of efficiency between 0 and 1 (Hussein, 1989; Greene, 1991). That is, the distribution of efficiency is censored above from unity. Estimation with OLS regression of the efficiency score would lead to a biased parameter estimate since OLS regression assumes normal and homoscedastic distribution of the disturbance and the dependent variable (Greene, 2003). To examine the role of relevant farm-specifics in production efficiency, the following Tobit model was estimated.

$$
\begin{aligned}
. E_{\mathrm{i}}^{*}=\sum_{\mathrm{j}} \beta_{\mathrm{j}} Z_{\mathrm{j}}+\mathrm{v}_{\mathrm{i}} & \\
E_{i}=1 & \text { if } E_{i}^{*} \geq 1 \\
E_{i}=E_{i}^{*} & \text { if } E_{i}^{*}<1
\end{aligned}
$$

Where $E_{i}$ is an efficiency score, representing technical, allocative and economic efficiencies; and $v \sim \mathrm{N}\left(0, \sigma^{2}\right)$ and $\beta_{j}$ are the vector of parameters to be estimated. $Z_{j}$ represent various farm specific variables and $E_{i}^{*}$ is the latent variable, with $E\left[E_{i}^{*} \mid X_{i}\right]$ equals $X_{i} \beta$.

\section{Result and Discussions}

\section{Estimates of Production and Cost Functions}

The stochastic production frontier was applied using the maximum likelihood estimation procedure. The dependent variable of the estimated production function was barley output (qt) produced in 2012/13 production season and the input variables used in the analysis were area under barley (ha), oxen (oxen-days), labor (man-days in manequivalent), quantity of seed $(\mathrm{kg})$ and inorganic fertilizers $(\mathrm{Kg})$. To include those farmers who did not apply inorganic fertilizers in the estimation of the frontier a very small value that approaches zero was assigned for nonusers of fertilizers, so as to estimate their outcomes.

Table 1. Estimates of the Cobb Douglas frontier production function

\begin{tabular}{llll}
\hline Variables & Coefficients & Std. Err. & Elasticities \\
\hline Ln(Inorganic fertilizers) & $0.076^{* * *}$ & 0.024 & 0.076 \\
Ln (Seed) & $0.118^{* *}$ & 0.050 & 0.118 \\
Ln( Land) & $0.040^{*}$ & 0.021 & 0.040 \\
Ln (Labour) & $0.332^{* * *}$ & 0.049 & 0.332 \\
Ln(Oxen) & $0.473^{* * *}$ & 0.060 & 0.473 \\
Constant & $1.878^{* * *}$ & 0.199 & \\
Lambda & $1.803^{* * *}$ & 0.048 & \\
Sigma square & $0.766^{* * *}$ & 0.922 & \\
\end{tabular}

Return to scale 1.039

$\backslash * * *, * *$ and $*$ show significance at $1 \%, 5 \%$ and $10 \%$ probability level, respectively Source: model output

The result of the model showed that all the input variables in the production function; i.e inorganic fertilizers (i.e. both DAP and Urea), area under barley, oxen (OD), labour (MD) and seed had a positive and significant effect on the level of barley output. The coefficients of the production function are interpreted as elasticity. Hence, high elasticity of output to oxen (0.473) suggests that barley production was relatively sensitive to oxen. As a result, 1 percent increase in number of oxen (OD) will result in 0.473 percent increase in the barley production, keeping other factors constant. Alternatively, this indicates barley production was responsive to oxen, followed by labor, seed, inorganic fertilizers and land respectively.

The returns to scale analysis can serve as a measure of total factor productivity (Gbigbi, 2011). The coefficients were calculated to be 1.039 , indicating increasing returns to scale (Table 1). This implies that there is potential for barley producer farmers to continue to expand their production because they are in the stage I of production, where resource use and production is believed to be inefficient. In other words, a percent increase in all inputs proportionally will increase the total production by 1.039 percent. This result is consistent with Solomon (2012) who estimated the returns to scale to be $1.04 \%$ in his study of EE of wheat seed production in Womberma woreda. But a study by Gbigbi (2011) in Nigeria found returns to scale to be 0.85 , which falls in stage II of production surface.

The ratio of the standard error of $\mathrm{u}\left(\sigma_{\mathrm{u}}\right)$ to the standard error of $\mathrm{v}\left(\sigma_{\mathrm{v}}\right)$, known as lambda $(\lambda)$, was 1.803 . Based on $\lambda$, gamma $(\gamma)$ which measures the effect of technical inefficiency in the variation of observed output can be derived (i.e. $\gamma=\lambda^{2} /\left[1+\lambda^{2}\right]$ ). The estimated value of gamma was 0.765 which indicated that $76.5 \%$ of total variation in barley farm output was due to technical inefficiency.

The dual frontier cost function derived analytically from the stochastic production frontier shown in Table 1 is given as: 


$$
\begin{aligned}
& \ln C_{i}=7.480+0.0743 \ln Y_{i}^{*}+0.017 \ln \omega_{\text {land }}+0.115 \ln \omega_{\text {seed }}+0.040 \ln \omega_{\text {Inorgfertilizers }} \\
& +0.112 \ln \omega_{\text {ox }}+0.176 \ln \omega_{\text {labour }}
\end{aligned}
$$

(4.1)

Where $\mathrm{C}$ is the minimum cost of production of the $\mathrm{i}^{\text {th }}$ farmer, $\mathrm{Y}^{*}$ refers to the index of output adjusted for any statistical noise and scale effects and $\omega$ stands for input prices.

\section{Efficiency scores}

The model output presented in Table 2 indicates that farmers in the study area were relatively good in TE than AE or EE. The mean TE was found to be $78.20 \%$. It indicated that farmers on average could decrease inputs (land, labor and fertilizers) by $21.8 \%$ if they were technically efficient. In other words, it implied that if resources were efficiently utilized, the average farmer could increase current output by $21.8 \%$ using the existing resources and level of technology. Similarly, barley producer farmers can save 53.95\% of their current cost of inputs by behaving in a cost minimizing way. Conversely, EE of $35.26 \%$ prevails that an economically efficient farmer can produce $64.74 \%$ additional barley.

Table 2. Summary statistics of efficiency measures

\begin{tabular}{lllll}
\hline Type of efficiency & Minimum & Maximum & Mean & Std. Deviation \\
\hline TE & 0.27 & 0.95 & 0.7820 & 0.10495 \\
AE & 0.26 & 0.94 & 0.4605 & 0.07760 \\
EE & 0.19 & 0.39 & 0.3526 & 0.01707 \\
\hline
\end{tabular}

Source: model output

\section{Determinants of efficiency differential among farmers}

The estimates of the Tobit regression model showed that among 15 variables used in the analysis, age, education, total cultivated land, extension contact, family size, land fragmentation, total expenditure, soil fertility, off/nonfarm income, sex, crop rotation and livestock ownership were found to be statistically significant in affecting the level of TE of farmers.

The model also revealed that age, education, total cultivated land, extension contact, training, land fragmentation, distance of the farm from home of farm households, total expenditure, crop rotation and livestock ownership were found to significantly influence allocative efficiency of barley producers. However, the sign for extension contact in allocative efficiency was not as anticipated. The result of the model further showed that age, education, training, family size, soil fertility, off/non-farm income, crop rotation and livestock ownership were important factors influencing economic efficiency of farmers in the study area (Table 3 ).

\begin{tabular}{|c|c|c|c|c|c|c|}
\hline \multirow[t]{2}{*}{ Variables } & \multicolumn{2}{|l|}{ TE } & \multicolumn{2}{|l|}{$\mathbf{A E}$} & \multicolumn{2}{|l|}{ EE } \\
\hline & $\begin{array}{l}\text { Marginal } \\
\text { Effect }\end{array}$ & Stad.Err. & $\begin{array}{l}\text { Marginal } \\
\text { Effect }\end{array}$ & Stad.Err. & $\begin{array}{l}\text { Marginal } \\
\text { Effect }\end{array}$ & Stad.Err \\
\hline Agehh & $0.002 * *$ & 0.000 & $0.003 * * *$ & 0.000 & $0.001 * * *$ & 0.000 \\
\hline EDUCLVL & $0.032 * * *$ & 0.008 & $0.029 * * *$ & 0.006 & $0.017 * * *$ & 0.003 \\
\hline TOTCULND & $0.019 * *$ & 0.007 & $0.118 * *$ & 0.005 & 0.001 & 0.002 \\
\hline EXTCT & $0.058 *$ & 0.031 & $-0.040 *$ & 0.025 & 0.003 & 0.010 \\
\hline TRNING & 0.002 & 0.030 & $0.066^{*}$ & 0.024 & $0.023^{* *}$ & 0.009 \\
\hline FAMSIZE & $0.015^{* * *}$ & 0.003 & -0.003 & 0.003 & $0.003 * * *$ & 0.001 \\
\hline LANDFRAG & $-0.019 * * *$ & 0.006 & $-0.009 * *$ & 0.005 & -0.000 & 0.002 \\
\hline DISTFRM & -0.008 & 0.007 & $-0.019 * * *$ & 0.005 & -0.002 & 0.002 \\
\hline TOTEXP & $-0.000 *$ & 0.000 & $-0.000 * *$ & 0.000 & -0.000 & 0.000 \\
\hline FERT & $0.029 *$ & 0.018 & 0.013 & 0.014 & 0.009 & 0.006 \\
\hline CRDT & 0.005 & 0.020 & 0.016 & 0.017 & 0.001 & 0.006 \\
\hline OFARM & $0.092 * * *$ & 0.016 & 0.006 & 0.013 & $0.033 * * *$ & 0.005 \\
\hline SEXHH & $0.032 *$ & 0.024 & 0.063 & 0.020 & 0.005 & 0.008 \\
\hline Croprtn & $0.243 * * *$ & 0.045 & $0.081 * *$ & 0.036 & $0.088 * * *$ & 0.014 \\
\hline TLU & $0.003 * *$ & 0.001 & $0.002 * *$ & 0.001 & $0.002 * * *$ & 0.000 \\
\hline Constant & $0.678 * * *$ & 0.092 & $0.554 * * *$ & 0.074 & $0.348 * * *$ & 0.017 \\
\hline
\end{tabular}

Table 3. Tobit model estimates for different efficiency measure

Where: $* * *$ and $* * *$ refers to $10 \%, 5 \%$ and $1 \%$ significance level, respectively.

Source: Model output, 2014

The discussion about each significant variable are presented as follows:

Age: The estimated coefficients of age for technical efficiency was positive signs and significant at 5 percent. As to the interpretation of marginal effects, for example, the marginal effect of 0.002 for age (technical efficiency) 
shows that, for sample period, an increase in age by one year led, on average, to an increase in technical efficiency by 0.002 . The result is similar with the findings of Abdulai and Eberlin (2001), Dolisca and Curtis (2008) and Dawang et al. (2011), which may be because of the accumulated experiences that have been gathered over time. They become skillful as they get older and may have an interest in the use of new methods of production. The estimated coefficients of age for allocative and economic efficiencies were also positive and significant at 1 percent significance level. This may be because allocative efficiency requires greater knowledge and skill gathered over time, which increases the capacity of farmers for optimal allocation of resources and technology. Therefore, the older the farmers are the more technically, allocatively and economically efficient they are.

Education: The coefficient of education is positive estimated coefficients for all efficiencies and significant at 1 percent. Positive and significant impact of education on all types of efficiencies confirms the importance of education in increasing the efficiency of barley production. It is a variable that is expected to increase managerial ability and led to good decisions in farming. Because of their better skills, access to information and good farm planning; literate farmers are better to manage their farm resources and agricultural activities and willing to adopt improved production technologies than illiterate one. It increases technical efficiency of the barley producers' farmers in the study area. This is in line with earlier studies by Jema and Andersson (2006) and Dawang et al. (2011). Besides this, educated farmers have relatively better capacity for optimal allocation of inputs. In line with this study, research done by Abdul (2003), Arega and Rashid (2005) in Eastern Ethiopia, Ogundari and Ojo (2007), Kehinde and Awoyemi (2009), Himayatullah et al. (2011), found education to influence AE and EE positively and significantly.

Land size: Total cultivated or farm land was found to have significant and positive impact on TE and AE, which is in line with the hypothesis made. This might be because of Farmers with larger area of cultivated land have the capacity to use compatible technologies that could increase the efficiency of the farmer, enjoy economies of scale. This result is in line with the argument of Andreu (2008). Therefore, larger farms are relatively better efficient than small size farms.

Extension contact: The coefficient for the access to extension has statistically significant positive relationship with technical efficiency at 10 percent. Similar results were obtained by Binam et al. (2004), Jema and Andersson (2006), Bozoglu et al. (2007), Mbanasor et al. (2008) and Jude et al. (2011). The positive estimated coefficient for contact with extension workers implies that efficiency increases with the number of visits made to the farm household by extension workers. However, the negative coefficient of extension contact which is significant in $\mathrm{AE}$ indicates that efficiencies in resource allocation are deteriorating as the frequency of extension contact increases. Moreover, during the survey, most farmers explained that they do not have new skills and information they learn from development agents. There are development agents who agree with the farmers concern. If this is the case, the contact with extension agent will only result in under-utilization of resources, giving a negative relationship with allocative efficiency.

Training: Training is an important tool in building the managerial capacity of the farmers. Farmers who received training was hypothesized to be more efficient than those who did not received training. The marginal effect for dummy variable, training indicates that if a farmer has access to training, for example, his allocative efficiency score will increase by 0.066 . The coefficient of training is positive for allocative and economic efficiencies and statistically significant at 10 and 5 percent significance level respectively. This may be because training enables them to use inputs in cost minimizing input ratio. This result is in line with the finding of Nejuma (2012).

Family size: The coefficient of family size for technical efficiency is positive and statistically significant at 1 percent significance level. The result is similar to the previous expectation that farmers those having large family size are more efficient than farmers having small family size, because; family labor is the main input in crop production as the farmer has large family size he would manage crop plots on time and may able to use appropriate input combinations. This is in line with the findings of Mohammed et al. (2009), Essa (2011) and Oluwatusin (2011). In similar manner, the coefficient of family size for economic efficiency is also positive and statistically significant at 1 percent. This might be because farmers with large family size had better capacity for optimal allocation of resources. This result is in line with the results of Okoruwa et al., (2006).

Land fragmentation: The coefficient of land fragmentation for technical efficiency is negative and statistically significant at 1 percent. The result confirms with the previous expectation, because fragmented land leads to inefficiency by creating shortage of family labour, wastage of time and other resources that should been available at the same time. Moreover, as the number of plots operated by the farmer increases, it may be difficult to manage these plots. In the study area land is fragmented and scattered over different places. Thus, farmers that have large number of plots may waste time in moving between plots. The result is in line with the finding made by Fekadu (2004). A similar result was obtained for allocative efficiency and it is negatively significant at 5 percent. This result is also in line with the expectation made. This might be because fragmented land is less cost efficient than consolidated one.

Farm to home distance: Distance of the farm from the home of household head was also significant in determining allocative efficiency. The negative coefficient implies that farmers far from farm of household head 
are less allocatively efficient compared to their counter-parts. This may be because of farmers near farm were incurred less cost compared to his counter-parts. Thus, leads to maximum output at least cost. The result is in line with the finding made by Alemayehu (2010).

Total expenditure: Household expenditure has turn out to have negative and significant effect on TE. This shows, as in the case of Jema (2008), households with much expenditure are usually constrained to buy inputs that would support their agricultural activities. In the same manner, it has also a negative and significant impact on allocative efficiency because; it may competes with limited cash available.

Soil fertility: The result also indicated that soil fertility was positively and significantly related to technical efficiency. This implies that farmers who allocated a land which was relatively fertile were good in technical efficiency. Therefore, decline in soil fertility could be taken as cause for significant output loss. The result is in line with the findings of Fekadu (2004) and Alemayehu (2010).

Off/non-farm income: The coefficient of off/non-farm activity with respect to technical efficiency is statistically significant at 1 percent. The result is in line with the findings of Beshir (2011) and Abebayehu (2011). Off/nonfarm occupation may affect the technical efficiency positively for the reason that the income obtained from such activities could be used for the purchase of agricultural inputs and augments financing of household expenditures which would entirely dependent on agriculture. It is also positive and significant at 1 percent for economic efficiency. This may be because; the availability of off/non-farm income shifts the cash constraint outwards and enables farmers to make timely purchases of those inputs which they cannot provide from on farm income. Therefore, it enables farmers in maximizing its output at efficient cost of production.

Sex: Sex of household head was found to have positive and significant impact on TE at 10 percent, which is in line with the hypothesis made. Furthermore, as expected, male households were more efficient than female households. The possible explanation is that male households might have better practical experiences in farming. Also, one might argue that female households are too much occupied with domestic activities and had little time for the management of their barley plots that led to low technical efficiency levels. The result is in line with the finding of Aynelam (2006).

Crop rotation: Crop rotation is a dummy variable which represents whether the farmer adopted crop rotation practice or not. It was hypothesized that farmers who practiced crop rotation could be more efficient than his/her counter-parts, as it helps to increase output by recycling and restoring nutrients required for barley production and may be result in reduction in costs. It is statistically significant for technical, allocative and economic efficiency at $1 \%, 5 \%$ and $1 \%$ percent significance levels respectively. The result is in line with the argument made by Musa (2013).

Livestock (TLU): The coefficient of livestock ownership for technical and allocative efficiency is positive and statistically significant at 5 percent. It was also positive and statically significant for economic efficiency at 1 percent significance level. Positive and significant impact of livestock ownership on technical efficiency may due to the importance of livestock in the crop production system (as source of draft power, income and manure) that may help to maintain soil fertility and result in maximization of output. In similar manner, positive and significant impact of livestock ownership on AE and EE as in the case of Wondimu (2010), confirms the considerable contribution of livestock in reducing the current cost of inputs in barley production.

\section{Summary, Conclusion and Recommendations Summary and Conclusion}

Agricultural sector in Ethiopia is characterized by its poor performance, whereas the population of the country, which to a large extent depends on agriculture, is growing at a faster rate. This necessitates seeking for a means to increase agricultural productivity of smallholder farmers, the dominant producers, which could either be met through improving the state of technology or enhancing the efficiency of producers. Alternatively, productivity growth may attribute to either technological progress or efficiency improvement. Improving efficiency of the farmer plays a vital role in increasing productivity, given the current state of technology. This study analyzed the technical, allocative and economic efficiencies and factors that explain the variation in efficiency among barley producers' farmers in Chole district of East Arsi zone, Oromia National Regional State.

The Cobb-Douglas stochastic frontier production and its dual cost functions were estimated from which TE, $\mathrm{AE}$ and $\mathrm{EE}$ estimates were extracted. The results from the production function indicated that inorganic fertilizers, area, human labour, oxen labour and seed were positively and significantly determining barley production. The positive coefficients of these parameters indicate that increased use of these inputs will increase the production level to a greater extent. The study also indicated that $78.20 \%, 46.05 \%$ and $35.26 \%$ were the mean levels of TE, $\mathrm{AE}$ and $\mathrm{EE}$, respectively. This in turn implies that farmers can increase their barley production on average by $21.8 \%$ when they were technically efficient. Similarly, they can reduce current cost of inputs, on average, by $53.95 \%$ if they were allocatively efficient. This implies that, using the subsisting resource base, improved efficiency can still be achieved and there was a great potential for increasing the gross output and profit with the existing level of resource base. 
In the other part of the analysis, relationships between TE, AE, and EE, and various variables that were expected to have effect on farm efficiency were examined. This was relied on Tobit regression techniques, where $\mathrm{TE}, \mathrm{AE}$, and EE were expressed as functions of 15 explanatory variables. Among them, age, education, total cultivated land, extension contact, family size, land fragmentation, total expenditure, soil fertility, off/non-farm income, sex, crop rotation and livestock ownership were found to be statistically significant to affect the level of technical efficiency. Furthermore, the results revealed that age, education, total cultivated land, extension contact, training, land fragmentation, distance of the farm from home of household head, total expenditure, crop rotation and livestock ownership significantly influence allocative efficiency of smallholders in the study area. However, the sign of the coefficients for extension contact in allocative efficiency was not as expected. The model also indicated that age, education, training, family size, off/non-farm income, crop rotation and livestock ownership were important factors that affect economic efficiency of farmers in the study area.

According to the finding of this study, farmers producing barley can increase their production at the existing level of technology and inputs through improving efficiency. Besides this, farmers can produce the same amount of output with lesser amount of inputs or they can produce more than the current output level with the same amount of input they are currently using if they are technically, allocatively and economically efficient. Moreover, the study contributes to improve farm revenue, welfare and generally helps agricultural as well as economic development.

\section{Recommendations}

Arising from the results of the study, the following recommendations are drawn:

Education was very important determining factor that has a positive and significant impact on TE, AE and EE in the study area. Thus, government has to give due attention for training farmers through strengthening and establishing both formal and informal type of farmers' education, farmers' training centers, technical and vocational schools as farmer education would reduce technical, allocative and economic inefficiencies.

Total cultivated land was found to be related to technical and allocative efficiencies level positively. This shows that with increased cultivated area, technical and allocative efficiencies of barley production would increase. This might be because of farmers with larger area of cultivated land have the capacity to use compatible technologies that could increase the efficiency of the farmer, enjoy economies of scale. Thus, provision of technologies that would help to carry out such operations more efficiently would improve the technical and allocative efficiencies level of the farmers and complementary inputs including employment of labor.

The result of the finding also indicated that extension contact has positive and significant effect on technical efficiency. Since extension services are the main instrument used in the promotion of demand for modern technologies, appropriate and adequate extension services should be provided. This could be done by designing appropriate capacity building program to train additional development agents to reduce the existing higher ratio of farmers to development agents as well as to provide refreshment training for development agents. The work also indicated that extension contact has negative and significant effect on allocative efficiency. This means that additional effort should be devoted to upgrade the skills and knowledge of the development agents so that farmers could gain from their presence. Such an effort must also focus on liking modern farming practice with the indigenous knowledge and to the institutional and socio-economic problems in the area.

Training is positively related to allocative and economic efficiencies of barley production. This indicates that training is fundamental in improving the $\mathrm{AE}$ and $\mathrm{EE}$ thereby the performance of farmers. Therefore, the regional government or district bureau of agriculture should have a prime responsibility to keep on the provision of training, in these areas and others so that farmers can use the available inputs more efficiently under the existing technology level.

Total expenditure of the household for non-agricultural activities has a negative impact in TE and AE of barley production. Hence, there should to have strong work on awareness creating on efficient allocation of resources, mainly cash.

The analysis also indicated that soil fertility is a crucial factor in determining technical efficiency. Therefore, farmers have to work to improve the fertility status of their farm though it is difficult to achieve this in the short run. Farmers can do this through improved land management practices and practicing soil conservation practices. Policy makers need also to have soil fertility maintenance program and extension workers can play a great role in improving the status of the soil by working closely with the farmers in this regard.

On the other hand, female households were found to be less technically efficient than their male households. This may be due to the fact that female headed households are too busy with domestic activities and had less time to manage their farm plots. Thus, promoting improved technologies (cooking stoves) that reduce the domestic burden of the female household heads would improve their technical efficiency level in barley production.

Crop rotation was also another significant factor that affects TE, AE and EE efficiency positively. Therefore, concerned government bodies; like extensions workers, Rural and Agricultural development offices and others have to work more on practices of following crop rotation by giving appreciation to the existing situation of the 
farmers in the study area.

Given the mixed farming system in the study area, farmers with better number of livestock were relatively better in technical, allocative and economic efficiencies of barley production. Hence, technologies that would support the production and productivity of livestock should be adopted, which in turn will enhance the overall efficiency of barley production.

Finally, it is interesting to note that most efficiency studies in the developing countries have focused mainly on the measurement of technical efficiency, even though it is by improving the overall economic efficiency that major gains in production could be achieved. This means, additional efforts should be devoted to examining the impact of both allocative and economic efficiencies on performance for different types of crops and areas at various points in time.

\section{References}

Abdul, W., 2003. Technical, Allocative and Economic Efficiency of Farm in Bangladesh: A Stochastic and DEA Approach. Journal of Developing Areas, 37(1): 109-126.

Abdulai, A. and R. Eberlin, 2001. Technical Efficiency during Economic Reform in Nicaragua: Evidence from Farm Household Survey Data. Economic Systems, 25: 113-125.

Abebayehu Girma, 2011. Technical Efficiency Analysis of Haricot Bean Seed Production: The Case of Boricha District, Sidama Zone, Southern Ethiopia. Unpublished M.S.c Thesis Presented to the School Graduate Studies of Haramaya University.

Alemayehu Ethiopia, 2010. Analysis of Factors Affecting the Technical Efficiency of Coffee Producers in Jimma Zone: A Stochastic Frontier Analysis. M.Sc. Thesis Presented to the School of Graduate Studies of Addis Ababa University.

Arega, D. and M.H. Rashid, 2005. The Efficiency of Traditional and Hybrid Maize Production in Eastern Ethiopia: An Extended Efficiency Decomposition Approach. Journal of African Economics, 15: 91-116.

Andreu, L.M., 2008. Studies on the Economic Efficiency of Kansas Farms. Doctoral Thesis Submitted to Kansas State University.

Badr A., 2000. On the Origin and Domestication History of Barley (Hordeum Vulgare). Molecular Biology and Evolution, 17: 499-510.

Beshir Hassen, 2011. Performance of Mixed Crop-Livestock Production System: The Data Envelopment Approach. Livestock Research for Rural Development. Volume 23, Article \#200.

Binam, J.N., J. Tonye, N. Wandji and M. Akoa, 2004. Factors Affecting the Technical Efficiency among Smallholder Farmers in the Slash and Burn Agriculture Zone of Cameroon. Food Policy, 29: 531-545.

Bozoglu, M. and V. Ceyhan, 2007. Measuring the Technical Efficiency and Exploring the Inefficiency Determinants of Vegetable Farms in Samsung Province Turkey. Agricultural Systems, 94: 649-656.

Coelli, T.J. and G.E. Battesse, 1995. A Model of Technical Efficiency Effects in Stochastic Frontier Function for Panel Data. Journal of Empirical Economics, 20: 325-332.

Coelli, T.J., D.S.P. Rao and G.E. Battese, 1998. An Introduction to Efficiency and Productivity Analysis. Kluwer Academic Publishers, Boston, Dordrecht/London, P, 134-249.

Crissman, C., F. Anderson, K. K. Kapinga, R. Lemanga, B. Devaux, A. Thiele, G. Ilangtileke, and C. Bussink, 2006. Global Trend in the Potato and Sweet Potato Sectors and Contributions to the Millennium Development Goals, 14th ISTRC Symposium, 20-26 November, 2006, Kerala, India.

CSA (Central Statistical Agency), 2008. Population and Housing Census Report, Addis Ababa, Ethiopia.

CSA (Central Statistics Agency), 2012. Annual Statistics Bulletin. Addis Ababa, Ethiopia.

CSA (Central Statistical Authority), 2013. Statistical Report on population projected figures for the year 2012, Addis Ababa, Ethiopia.

CDARDO (Chole District Agriculture and Rural Development Office), 2013. Chole District Agriculture and Rural Development Office, Annual Report. Chole, Ethiopia.

Dawang, N., and Y. Oseni, 2011. Determination of Economic efficiency of Integrated Crop production System: A Case from Plateau State, Nigeria. World Journal of Agricultural Science, 7: 467-475.

Dolisca, F. and M.J. Curtis, 2008. Technical Efficiency of Traditional and Non-Traditional Crop Production: A Case Study from Haiti. World Journal of Agricultural Sciences, 4: 416- 426.

EEA (Ethiopian Economic Association), 2012. Annual Report on Ethiopian Economy. Addis Ababa, Ethiopia.

Essa Chanie, 2011. Resource Use Efficiency of Smallholder crop Production in the Central Highlands of Ethiopia. MSc. Thesis Presented to Department of Agricultural Economics and Business Management, Egerton University, Kenya.

Farrell, M.J., 1957. The Measurement of Productive Efficiency. Journal of Royal Statistical Society, Series A, 120: $253-290$.

Fekadu Gelaw, 2004. Analysis of Technical efficiency of Wheat production: A study in Machakel Woreda, Ethiopia. An M.Sc Thesis Presented at Alemaya University. 
Getu Hailu, 1997. Analysis of Performance Variation: The Case of Smallholder Farms in Eastern Hararghe Region. An M.Sc. Thesis Presented at Alemaya University.

Gbigbi, M., 2011. Economic Efficiency of Smallholder Sweet Potato Producers in Delta State, Nigeria: a Case Study of Ughelli South Local Government Area. Research Journal of Agriculture and Biological Sciences, 7: $163-168$.

Green, W. (1991) LIMPED: Users's Manual and Reference Guide, New York: Econometric Software, Inc.

Greene, W.H., 2003. Econometrics Analysis. $5^{\text {th }}$ edition. New York: New York University.

Himayatullah K. and S. Imranullah, 2011. Measurement of Technical, Allocative and Economic Efficiency of Tomato Farms in Northern Pakistan. Paper Presented at International Conference on Management, Economics and Social Sciences (ICMESS'2011), Bangkok.

Hussain, S. (1989) Analysis of Economic Efficiency in Northern Pakistan: Estimation, Causes and Policy Implications, phD. Desertation, University of Illinois.

Jema Haji, 2008. Economic Efficiency and Marketing Performance of Vegetable Production in the Eastern and Central Parts of Ethiopia. Doctoral Thesis Presented to Swedish University of Agricultural Sciences.

Jema Haji and H. Andersson, 2006. Determinants of Efficiency of Vegetable Production in Smallholder Farms: The Case of Ethiopia. Food Economics, 3: 125-137.

Jude, C., C. Benjamen and C. Patrick, 2011. Measurement and Determinants of Production Efficiency among Smallholder Sweet Potato Farmers in Imo State, Nigeria. European Journal of Scientific Research, 59 (3): 307-317.

Kaleab Kebede, 2010. Analysis of Technical Efficiency, Empirical Evidence from Wheat Producing Smallholder Farmers and Commercial Farms in Bale Zone of Oromiya, Ethiopia. An M.S.c. Thesis Presented to School of Graduate Studies of Haramaya University.

Kinde Teshome, 2005. Technical Efficiency of Maize Production: A Case of Smallholder Farmers in Assosa Woreda. Unpublished M.S.c. Thesis Presented to School of Graduate Studies of Haramaya University.

Kehinde, A.L. and T.T. Awoyemi, 2009. Analysis of Economic Efficiency in Sawnwood Production in South West Nigeria. Journal of Human Ecology, 26(3): 175-183.

Kopp, R.J. and V.K. Smith, 1980. Frontier Production Function Estimates for Steam Electric Generation. A Comparative Analysis. Southern Economic Journal, 47: 1049-1059.

Kumbhakar, C. S., 1991. The Measurment and Decomposition of Cost-Inefficiency: The Translog Cost System. Economic Papers, 43: 667-683.

Mbanasor, J. and K.C. Kalu, 2008. Economic Efficiency of Commercial Vegetable Production System in Akwa Ibom state, Nigeria. Journal of Tropical and Subtropical Agroecosystems, 8(3): 313-318.

Mohamed, A., 2012. Economic Efficiency of Wheat Production in Gezira Scheme, Sudan. Journal of the Saudi Society of Agricultural Sciences, 11(1): 11-15.

Musa Hasen, 2013. Economic Efficiency of Smallholder Farmers Maize Production: The Case of Arsi Negelle District of West Arsi Zone. An MSc Thesis Presented to the School of Graduate Studies of Haramaya University.

Nejuma Mohammed, 2012. Economic Efficiency of Potato Production: The Case of Sheshemene District of West Arsi Zone. An MSc Thesis Presented to the School of Graduate Studies of Haramaya University.

Ogundari, K and S.O. Ojo, 2007. Economic Efficiency of Small Scale Food Crop Production in Nigeria: A Stochastic Frontier Approach. Journal of Social Science, 14(2): 123-130.

Oluwatusin, F., 2011. Measuring Technical Efficiency of Yam Farmers in Nigeria: A Stochastic Parametric Approach. Agricultural Journal, 6: 40-46.

Okoruwa, V.O., O.O. Ogundele and B.O. Oyewusi, 2006. Efficiency and Productivity of Farmers in Nigeria: A Study of Rice Farmers in North Central Nigeria. Poster Paper Prepared for Presentation at the International Association of Agricultural Economists Conference, Gold Coast, Australia.

Solomon Bizuayew, 2012. Economic Efficiency of Wheat Seed Production: The Case of Smallholders Womberma woreda, East Gojjam Zone. An MSc Thesis Presented to the School of Graduate Studies of Haramaya University.

Wondimu Saketa, 2010. Economic Efficiency of Export Oriented Crop Production in Ethiopia: The Case of Haricot Beans in Adama and Dugda districts, East Shewa zone of Oromia, Ethiopia. An MSc Thesis Presented to the School of Graduate Studies of Haramaya University.

Wadi'ah Maalouf 2012. Malt Barley Technical Production Efficiency in South Eastern Ethiopia. American Journal of Agricultural Sciences, 3(1): 2668-3725.

World Bank, 2007. Project Performance Assessment Report: Seed System Development Project and National Fertilizer Sector Project. Report No. 40124.

WFP (World Food Program), 2013. Summary of Food Security and Vulnerability in Selected Cities of Ethiopia. Yamane, T., 1967. Statistics: An Introductory Analysis, $2^{\text {nd }}$ ed. New York, Harper and Row. 